\title{
Left vertebral artery dissection causing bilateral internuclear ophthalmoplegia
}

\author{
Glen Jickling, MD; ${ }^{*}$ Kelvin Leung, BSc ${ }^{\dagger}$ Kenman Gan, MD; Ashfaq Shuaib, MD; ${ }^{*}$ \\ James Lewis, MD; $;$ Mikael S. Mouradian, MD ${ }^{\S}$
}

\begin{abstract}
A 21-year-old woman presented to the emergency department 1 day after a fall. On the day of presentation, she awoke with horizontal diplopia and posterior neck pain. Based on clinical findings, she was diagnosed with bilateral internuclear ophthalmoplegia. A conventional angiogram identified a left vertebral artery dissection. She was started on anticoagulant therapy, with gradual improvement of her diplopia over several months. Diplopia is frequently seen in the emergency department. Internuclear ophthalmoplegia is a cause of binocular diplopia and is important to recognize because it indicates a brainstem lesion requiring neurologic evaluation.
\end{abstract}

Keywords: bilateral internuclear ophthalmoplegia, vertebral artery dissection, diplopia

\section{RÉSUMÉ}

Une femme de 21 ans s'est présentée à l'urgence le lendemain d'une chute. Le jour de sa visite à l'urgence, elle avait au réveil une diplopie horizontale et des douleurs postérieures au cou. Les résultats cliniques ont permis de diagnostiquer une ophtalmoplégie internucléaire bilatérale. L'angiographie conventionnelle a révélé une dissection de l'artère vertébrale gauche. On a amorcé un traitement anticoagulant, et la diplopie s'est améliorée progressivement sur plusieurs mois. Il n'est pas rare de voir des cas de diplopie à l'urgence. L'ophtalmoplégie internucléaire étant une des causes de la diplopie binoculaire, il est important de pouvoir la diagnostiquer, car elle signale une lésion du tronc cérébral nécessitant une évaluation neurologique.

\section{Introduction}

Diplopia can present as either monocular or binocular impairment, implicating different anatomical structures and diseases. ${ }^{1}$ Monocular diplopia occurs when 2 images are seen in 1 eye and suggests an ocular problem. Binocular diplopia occurs when the eyes are misaligned and indicates a dysfunction of the ocular muscles or a component of the nervous system that controls them. One cause of binocular diplopia is internuclear ophthalmoplegia (INO), which is brought about by a lesion of the medial longitudinal fasciculus, a neural pathway in the brainstem that is involved in the control of horizontal eye movements. We present the case of a patient with bilateral INO secondary to a left vertebral artery dissection and discuss the diagnostic and management issues raised by this condition.

\section{Case report}

A 21-year-old woman presented to the emergency department (ED) with double vision, nausea and posterior neck pain, all of which were noted when she awoke. There was no 
associated weakness, numbness, vertigo, dysarthria, dysphagia or gait instability. She had fallen on ice the day before presentation but had been otherwise well. On physical examination, the patient was alert and oriented with normal vital signs. Her visual acuity was $20 / 20$ in both eyes and her pupils were equal and reactive at $3 \mathrm{~mm}$ with no relative afferent pupillary defect, ptosis or exophthalmos. She had full visual fields and her fundi were normal. On primary gaze, she had horizontal diplopia with exotropia (Fig. 1). On right lateral gaze, her left eye had limited adduction and her right eye showed horizontal nystagmus with the fast phase toward the right. On left lateral gaze, her right eye had limited adduction and her left eye showed horizontal nystagmus with the fast phase toward the left. She reported worsening of the diplopia with both right and left gaze. Convergence was intact and the remainder of her neurologic examination was unremarkable.

The patient's eye movements were consistent with bilateral INO. Magnetic resonance imaging of her brain showed no evidence of pontine infarction or demyelination. Magnetic resonance angiography, however, revealed a narrowing of the horizontal segment of her left vertebral artery. Conventional cerebral angiography was subsequently performed and confirmed a long dissection in the horizontal segment of her left vertebral artery (Fig. 2A).

After consultation with neurology, the patient was started on anticoagulant therapy to prevent further thromboembolic events. Her diplopia gradually improved over several months. Repeat conventional cerebral angiography was performed 6 months after her initial presentation and demonstrated recanalization of the left vertebral artery (Fig. 2B). Anticoagulant therapy was stopped and the patient was started on daily acetylsalicylic acid.

\section{Discussion}

The ED evaluation of diplopia is best approached by catego- rizing the complaint as either monocular or binocular. Monocular diplopia is generally caused by a disruption of light to the retina and requires ophthalmologic assessment. Binocular diplopia, in contrast, indicates ocular misalignment and can result from a number of etiologies including disorders of the ocular muscles, the neuromuscular junction, the ocular motor cranial nerves or the ocular motor nuclei. ${ }^{1}$

Our patient had binocular diplopia with bilaterally limited adduction on attempted lateral gaze and horizontal nystagmus of the abducting eye. These are the classic findings of bilateral INO, a syndrome which is important to recognize as it strongly suggests a lesion of the medial longitudinal fasciculus in the brainstem.

The 2 most common etiologies for INO, accounting for more than $70 \%$ of cases, are infarction or multiple sclerosis involving the pons (Box 1). ${ }^{2}$ Multiple sclerosis should be suspected in young patients with a history of typical neurologic impairments such as optic neuritis, sensory loss or transverse myelitis. A stroke is generally suspected in older patients with vascular risk factors. However, strokes from arterial dissection can occur in young patients and typically present with headache, neck pain and a history of

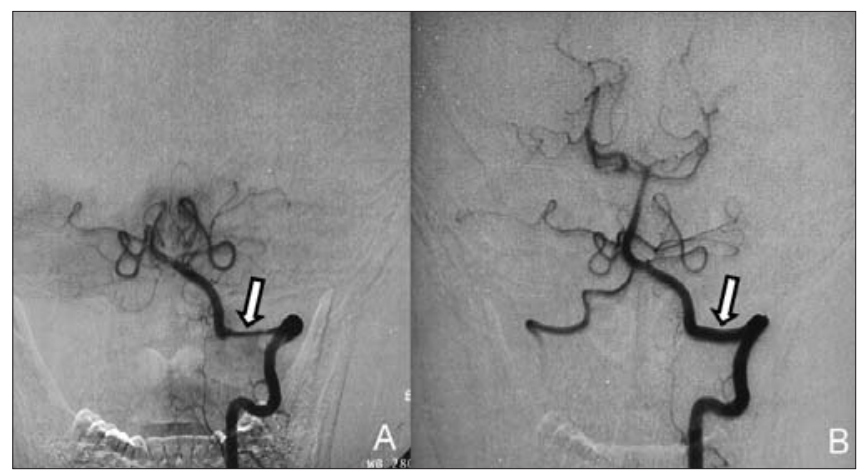

Fig. 2. Cerebral angiogram showing left vertebral artery dissection at presentation (A) and left vertebral artery recanalization 6 months later (B).

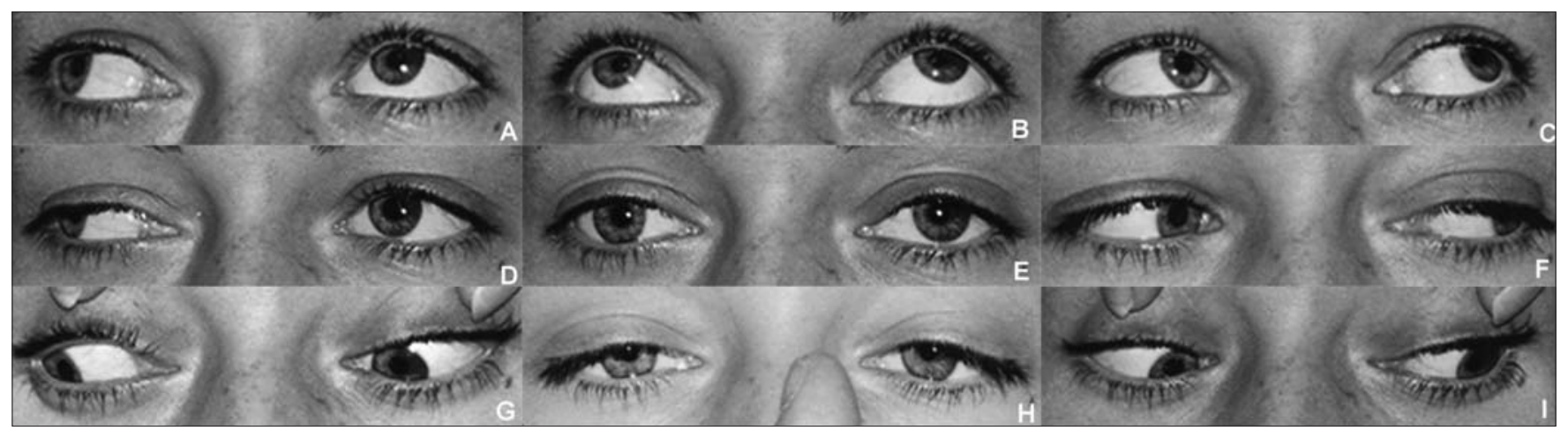

Fig. 1. Patient's eyes shown in various positions of gaze: right superior gaze (A); superior gaze (B); left superior gaze (C); right lateral gaze (D); primary position (E); left lateral gaze (F); right inferior gaze (G); convergence (H); left inferior gaze (I). 
mild trauma. Other less common etiologies of INO that are important to consider include head trauma, central nervous system infection, brainstem tumour and tentorial herniation. There are several conditions that can mimic INO and are thus termed pseudo-INO (Box 1). ${ }^{1}$ The clinical features associated with these conditions, such as fatigability in myasthenia gravis, and areflexia, autonomic instability and bifacial weakness in Guillain-Barré syndrome, help establish the correct diagnosis.

Bilateral INO is most often due to multiple sclerosis, but other causes such as ischemic stroke, trauma and brainstem tumour have been reported. ${ }^{3,4}$ Magnetic resonance imaging of the brain may fail to identify a brainstem lesion in $30 \%$ of patients with INO, as was the case with our patient. ${ }^{5}$ This is likely because an infarct that would impair both medial longitudinal fasciculus tracts yet spare other brainstem structures is extremely small.

Our patient was found to have a dissection of her left vertebral artery that was likely related to her recent fall. Such cervical artery dissections have an incidence of 1.5

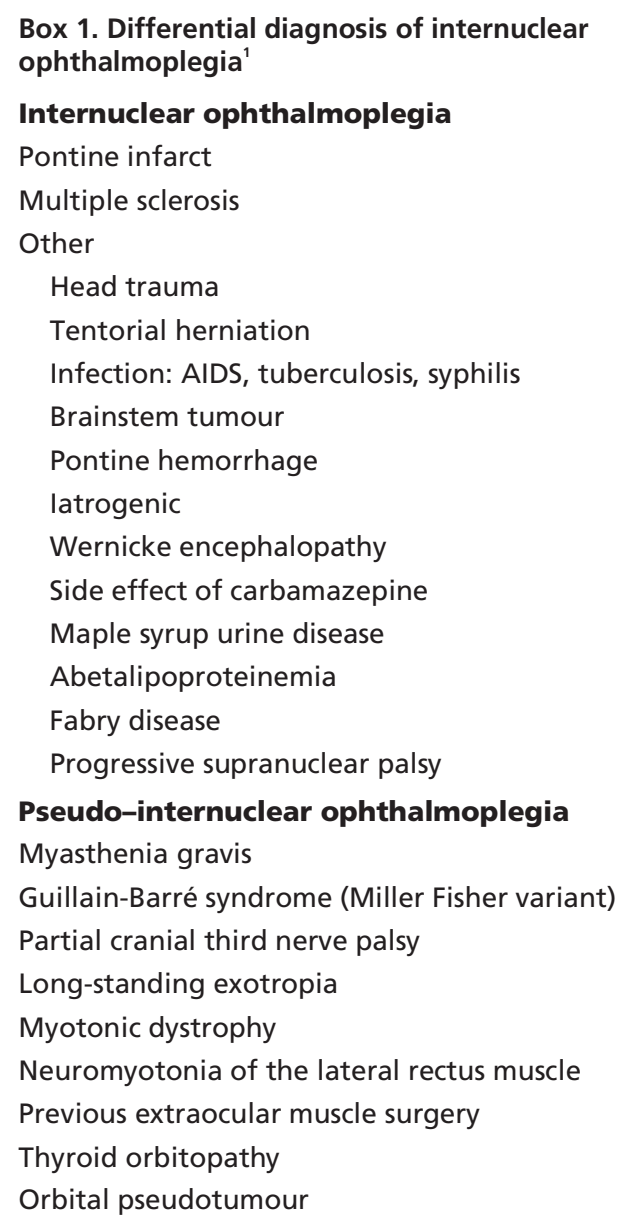

per 100000 per year and account for $20 \%$ of strokes in patients younger than 45 years of age. ${ }^{6}$ Dissections can be related to neck trauma or can occur spontaneously. Although no randomized controlled trials have been performed on the management of extracranial cervical artery dissection, consensus recommendations advise starting anticoagulant therapy as soon as the dissection is identified and continuing for 3 to 6 months until recanalization of the vessel occurs. ${ }^{7}$ In the presence of a large stroke, it is advised that anticoagulant therapy be delayed for 1 to 2 weeks to reduce the risk of hemorrhagic transformation. In some cases, stenting of the dissected segment can be performed; however, this remains experimental. ${ }^{8}$

\section{Conclusion}

The ED evaluation of diplopia is best approached by categorizing the complaint as either monocular or binocular. INO is a cause of binocular diplopia that can be localized without imaging to a lesion of the medial longitudinal fasciculus in the brainstem. It is frequently caused by multiple sclerosis or ischemic stroke, as the vertebral artery dissection found in our patient illustrates. INO is an important condition to recognize because it indicates a brainstem lesion requiring neurologic evaluation.

Competing interests: None declared.

\section{References}

1. Kline LB, Bajandas FJ. Neuro-ophthalmology review manual. Rev. 5th ed. Thorofare (NJ): Slack; 2004. p. 67-9.

2. Keane JR. Internuclear ophthalmoplegia. Unusual causes in 114 of 410 patients. Arch Neurol 2005;62:714-7.

3. Walsh WP, Hafner JF, Kattah JC. Bilateral internuclear ophthalmoplegia following minor head trauma. J Emerg Med 2003;24: 19-22.

4. Kim J S. Internuclear ophthalmoplegia as an isolated or predominant symptom of brainstem infarction. Neurology 2004;62: 1491-6.

5. Bolanos I, Lozano D, Cantú C. Internuclear ophthalmoplegia: causes and long-term follow-up in 65 patients. Acta Neurol Scand 2004;110:161-5.

6. Arnold M, Bousser MG, Fahrni G, et al. Vertebral artery dissection: presenting findings and predictors of outcome. Stroke 2006;37:2499-503.

7. Lyrer P, Engelter S. Antithrombotic drugs for carotid artery dissection. Cochrane Database Syst Rev 2003;(3):CD000255.

8. Cohen JE, Leker RR, Gotkine M, et al. Emergent stenting to treat patients with carotid artery dissection: clinically and radiologically directed therapeutic decision making. Stroke 2003;34: e254-7.

Correspondence to: Dr. Mikael S. Mouradian, 2121 Pease St., Ste. 1D, Harlingen TX 78550; mikael.muratoglu@valleybaptist.net 